\title{
IDEIAS, INTERESSES E ESCOLHA RACIONAL: \\ O CONGRESSO NACIONAL E O ACORDO \\ NUCLEAR BRASIL-ALEMANHA
}

\section{Rodrigo Morais Chaves ${ }^{1}$}

\section{Resumo}

Este artigo propõe uma interpretação sobre a mudança de posição do Congresso e seu papel pivotal na desestabilização do programa nuclear decorrente do Acordo de 1975. Aborda também a reorientação da política nuclear que se segue, à luz do modelo de persuasão política de Weingast, apontando como uma mudança de percepção sobre ideias em disputa reorienta as estratégias dos atores e os caminhos da política nuclear.

Palavras-Chave: Política Nuclear Brasileira; Institucionalismo; Escolha Racional

\section{Abstract}

This paper proposes an interpretation about the Congress' position shifting and its pivotal role in the destabilization of the Brazilian nuclear program. Based on Weingast's model of political persuasion, it also focuses the nuclear policy reorientation that follows this process, pointing how a change of perception about concurrent ideas reoriented actors' strategies and the Brazilian nuclear policy.

Key-words: Brazilian nuclear policy; institutionalism, rational choice

${ }^{1}$ Doutorando em História pelo Programa de Pós-Graduação em História da Universidade Federal de Juiz de Fora. E-mail: rodrigo_mch@hotmail.com 


\section{Introdução}

O Acordo Nuclear de 1975, assinado entre o Brasil e a República Federal da Alemanha, era até então o maior acordo de transferência de tecnologia nuclear já assinado. Previa a transferência de todas as etapas do ciclo do combustível nuclear, desde a mineração até seu efetivo uso, bem como a construção de 8 usinas no país.

Num primeiro momento, a maioria dos atores, em especial o Congresso, enxergavam a iniciativa com bons olhos. No entanto, em 1978, o Congresso instaurou uma CPI para investigar o acordo, num dos pontos altos de um processo de oposição ao tratado celebrado três anos antes, e que converteu-se num dos catalizadores de uma grande mudança institucional no setor nuclear. Somado a outros fatores, a perda de apoio ao programa no Congresso levou o governo a ampliar o insulamento burocrático do setor nuclear, estabelecendo um programa autônomo e secreto, com um desenho institucional e objetivos distintos, além de fundamentado em um conjunto diferente de ideias.

Este artigo propõeumainterpretaçãosobre a mudança de posição do Congresso e seu papel pivotal na desestabilização do programa nuclear decorrente do Acordo de 1975, bem como sobre a reorientação da política nuclear que se segue, à luz do modelo de persuasão política de Weingast. $O$ modelo será discutido em maior detalhe adiante, mas ao buscar os microfundamentos de processos que transcorrem nas chamadas conjunturas críticas, Weingast sublinha o papel das ideias e da interpretação na definição dos interesses e estratégias dos atores. Nesse sentido, é um modelo de escolha racional que busca fundamentar a noção de conjuntura crítica, cara ao institucionalismo histórico, tornando mais claros seus mecanismos e processos.

Para tanto, este artigo se divide em três partes. Na primeira será discutido o modelo de persuasão política de Weingast e seu uso na interpretação do caso levantado. Na segunda parte, será feita uma breve apresentação descritiva sobre o programa nuclear brasileiro criado a partir do Acordo de 1975, os principais atores envolvidos e suas perspectivas sobre o tema. Também será discutido como o programa perde sua base de sustentação no Congresso, levando, junto a outros fatores, o Executivo a criar um novo modelo institucional para o setor nuclear. Por fim, a última parte apresenta as conclusões, apontando que o papel pivotal do Congresso na erosão da base de apoio do Acordo de 1975 deveu-se não a uma mudança de interesses, mas a uma nova percepção sobre uma mesma 
ideia, capaz de mudar a estratégia adotada por este e outros atores relevantes para o processo. Aponta também o papel que a estrutura desempenhou, com as mudanças ocorridas a partir das eleições de 1974 e do distanciamento entre o regime civil-militar e a comunidade científica brasileira.

\section{Ideias, Interesse e Escolha: Um modelo para a análise}

Antes de mais nada, é necessária uma breve discussão sobre o conceito de conjuntura crítica, tendo em vista que o conceito tem diferentes acepções. Diversas interpretações do institucionalismo histórico trabalham com um modelo dual de desenvolvimento institucional: períodos marcados por estabilidade institucional, pontuados por breves períodos de instabilidade, onde grandes mudanças se tornam possíveis - as conjunturas críticas. Estas conjunturas, por sua vez, dão início a novas trajetórias estáveis (CAPOCCIA, KELEMEN, 2007; MAHONEY, THELEN, 2010). Estes pontos de vista centrados na noção de dependência da trajetória dão maior ênfase à fase de reprodução da instituição do que ao momento de mudança, desequilibrando a relação entre agência e estrutura, base desta discussão. Ademais, estas perspectivas concorrerem para uma relativa pobreza conceitual da noção de conjuntura crítica, muitas vezes tomada como não mais que um ponto de partida ou de chegada das análises.

Avançando sobre a lacuna que existe no que tange ao aparato intelectual existente para a análise das conjunturas críticas em relação aos processos de reprodução e estabilidade das instituições, Capoccia e Kelemen procuram definir a conjuntura crítica nos seguintes termos:

In institutional analysis critical junctures are characterized by a situation in which the structural (that is, economic, cultural, ideological, organizational) influences on political action are significantly relaxed for a relatively short period, with two main consequences: the range of plausible choices open to powerful political actors expands substantially and the consequences of their decisions for the outcome of interest are potentially much more momentous. Contingency, in other words, becomes paramount (2007, pp 343).

Tomando de empréstimo a definição referida acima, isto é, de uma conjuntura breve onde determinantes estruturais perdem muito do poder de constranger as ações e aumentam o leque de possiblidades dos atores, é possível entender 
Ideias, interesses e escolha racional, pp. 27 - 42

as mudanças institucionais na política nuclear brasileira de então através de um olhar centrado na dinâmica interna da conjuntura crítica, e não nos seus resultados enquanto um turning-point na trajetória de desenvolvimento das instituições.

As teorias do institucionalismo histórico, conforme mencionado acima, têm por hábito dar maior ênfase aos processos dependentes da trajetória, isto é, à continuidade, do que à mudança. Diversos autores buscaram utilizar métodos e ideias do institucionalismo da escolha racional para buscar os microfundamentos de conceitos como dependência da trajetória, por exemplo (NORTH, 1990 ; PIERSON, 2000). Weingast (2005), por sua vez, procura fazê-lo com a noção de conjuntura crítica, com vistas a compreender como indivíduos racionais podem

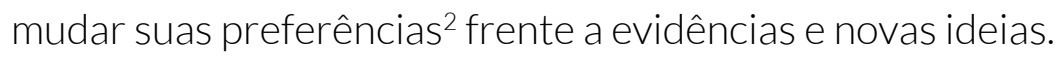

Seu modelo envolve a existência de um pivô (indivíduo ou grupo) cujo suporte é necessário para a manutenção do status quo e, por conseguinte, para sua mudança. Caso o pivô passe a apoiar uma ideia alternativa, o status quo perde estabilidade. Além dos pivôs, existem grupos intermediários, necessários para que os defensores do status ou da mudança consigam manter controle político.

Segundo o autor, os indivíduos possuem um modelo mental do mundo político em que vivem, e existe um modelo prevalente. Ou seja, um modelo partilhado pela maioria dos atores, que implica em visões específicas sobre as instituições e a política em geral. Existem também modelos alternativos, que se colocam em disputa com este modelo de aceitação geral, mas que padecem das desvantagens de que diversos atores já estão comprometidos com a ideia aceita, e que a mudança não raro implica em custos, além de estar marcada pela incerteza. Nesse sentido, a adoção de novas ideias depende da persuasão de atores pivotais:

For individuals to adopt a new idea, they must find it a persuasive way of organizing the world. In rational choice perspective, this requires not only that the new idea have logical and emotional appeal, but that evidence supports the new idea as a viable model of the world. As I suggest, a central aspect of political persuasion is that events beyond the direct control of the political entrepreneurs advocating the new idea help confirm the entrepreneur's views (WEINGAST, 2005, 163).

2 Em que pese haver uma discussão sobre interesses subjacentes e interesses manifestos, este trabalho toma interesse como as estratégias adotadas pelos atores frente à realidade, e não como um interesse exógeno ao contexto em que se insere, tampouco como uma preferência subjacente que não muda frente à realidade.

CSOnline - Revista Eletrônica de Ciências Sociais, Juiz de Fora, n. 27 (2018) 
O modelo aponta que a probabilidade de a ideia alternativa estar correta em geral é baixa, de modo que não mais que um pequeno grupo de defensores a levam a sério. Mas uma combinação precisa de novas ideias e eventos que as confirmem podem persuadir mais atores a encampá-la e, no limite, ultrapassar o "ponto crítico", isto é, o ponto a partir do qual o pivô muda sua posição e desestabiliza a ideia prevalente.

Outro aspecto central do modelo deriva da "racionalidade do medo", isto é, quando a aposta embutida na escolha entre alternativas políticas envolve apostas muito altas, o ponto crítico tende a ser menor. Em outras palavras, num cenário de incerteza que coloque em dúvida os compromissos centrais dos atores, eles se tornam mais receptivos a uma mudança que vise proteger esses valores e interesses, caros aos indivíduos. Por esta razão os proponentes de uma nova ideia se beneficiam ao apresentar as apostas como mais altas do que realmente são.

Daí decorre que não apenas as evidências podem mudar os interesses de atores, mas também sua percepção sobre o que está em jogo pode tornar uma ideia alternativa mais interessante. Os eventos externos mencionados acima, por exemplo, não precisam comprovar a ideia alternativa, mas apenas fazer com que os atores a percebam como verdade. Este modelo trabalha com uma noção de aprendizado num cenário de incerteza, portanto. Os atores não têm a possibilidade de interpretar o mundo sob ideias que são seguramente verdade, e tem que escolher entre alternativas com base em suas percepções sobre os custos e benefícios embutidos nessas escolhas.

Segundo o modelo, a mudança política será, então, descontínua. Uma mudança rápida na percepção dos atores, ancorada em eventos que a confirmem e que estão fora do controle de seus defensores, leva a uma rápida mudança de estratégias dos atores e, se envolver os atores pivotais (ou ator) leva a uma rápida reorientação política.

Este modelo mostra, em suma, como uma rápida reorientação política de atores racionais pode decorrer de novas ideias, bem como da interpretação sobre estas ideias, levando a uma mudança descontínua, brusca, na orientação da política e na adoção de modelos alternativos para enquadrar a realidade. 


\section{O Acordo Brasil-Alemanha: Atores e Processos, Ideias e Interesses}

A política nuclear brasileira vem desde a Era Vargas ${ }^{3}$. Foge ao escopo deste artigo discutir toda sua extensão, mas vale apontar os antecedentes mais recentes em relação ao Acordo de 1975.

A usina Angra I, em Angra dos Reis, foi construída após um acordo com a empresa norte-americana Westinghouse, em 1968. Um problema central do modelo de acordo criado, chamado à época de turn-key, isto é, um acordo onde a empresa vendia a usina, treinava técnicos brasileiros em sua operação, mas era responsável por eventuais manutenções e não transferia nenhum tipo de tecnologia (CAMARGO, 2006).

As características do acordo geraram críticas relativas ao estabelecimento de dependência externa no setor, a despeito das diretrizes aprovadas por Costa e Silva em 67 que postulavam a busca por autonomia e livre pesquisa no setor nuclear, como motor para o desenvolvimento ${ }^{4}$. Estas diretrizes informaram, contudo, os próximos passos da política nuclear brasileira.

Neste sentido, o Acordo de 1975 representou uma busca por autonomia tecnológica e energética do governo brasileiro, bem como por asserção política. Assinado em outubro de 1974 e ratificado no ano seguinte, o Acordo foi gestado em um contexto complicado. 1974 foi o ano do primeiro teste nuclear indiano, com uma bomba de plutônio construída com material desviado de um reator americano-canadense em operação no país, gerando novos esforços e receios em relação às políticas de não-proliferação. Foi também o ano em que os EUA suspenderam unilateralmente o contrato de venda de material físsil para Angra I, reforçando a crítica de que o acordo de 1968 criava dependência; e que a Eletrobrás lançou o "Plano 90", apontando a necessidade da energia nuclear como complemento à matriz energética brasileira. No plano econômico, o Brasil ainda se encontrava sob os efeitos do Choque do Petróleo de 1973 que ameaçava o modelo de desenvolvimento do regime civil-militar. No plano mais estritamente político, diferentemente das eleições de 1972, onde a ARENA

${ }^{3}$ De maneira mais detalhada em PATTI, C. Brazil in the Global Nuclear Order. Firenze, 2010, capítulos 1 e 2; e em CAMARGO, G. O Fogo dos Deuses: Uma História da Energia Nuclear. Rio de Janeiro, Editora Contraponto, 2006, dentre outros.

${ }^{4}$ As diretrizes foram discutidas em reunião do Conselho de Segurança nacional. Ata da Quadragésima Sessão do Conselho de Segurança Nacional. 1967 - Secreto. Arquivo Nacional, pg. 2. Disponível em http:// imagem.arquivonacional.gov.br/sian/arquivos/1013051_2564.pdf. 
obteve expressiva maioria dos assentos no parlamento, nas eleições de 1974 se fizeram sentir mudanças no alinhamento eleitoral dentro do sistema bipartidário ARENA-MDB, muito embora o governo ainda detivesse maioria 5 .

No entanto, apesar da mudança de proporções no Congresso, não houve uma elevação das críticas ao Acordo, assinado em junho de 1975. O acordo foi comemorado tanto pela oposição como pelos aliados do governo, ainda que de maneiras distintas. Contribuindo para que a balança pendesse mais acentuadamente para a aprovação do Acordo, a afirmação do senador americano John Pastore, Presidente da Comissão de Energia Atômica dos EUA, de que o acordo criava uma ameaça em seu "quintal" insuflou o nacionalismo em todo o espectro político brasileiro ${ }^{6}$. Com efeito, Coutto (2011) aponta que a clivagem governo/oposição não foi importante na recepção do acordo, mas que na verdade foi o nacionalismo ou ideias avizinhadas, como autonomia e independência, que deram a tônica da aceitação. Com efeito, as comunicações na tribuna do Senado apontam para isto:

José Sarney (ARENA) fez um discurso em que salientava a posição de independência do Brasil no campo nuclear, fazendo reverência ao presidente da Sessão Legislativa, Magalhães Pinto (ARENA), que quando Ministro das Relações Exteriores [...] formou as bases para a cooperação que se iniciaria em 1975. Seu discurso tratava a ocasião como "o início de nossa libertação tecnológica e a segurança de que seremos o único país no mundo ocidental a, em curto prazo, ser autossuficiente em energia”". Seu discurso foi secundado por membros do MDB, como Saturnino Braga e Mauro Benevides, este em nome da oposição. Benevides reiterou o apoio da oposição ao acordo desde sua gestação, por entendê-lo como uma importante iniciativa em longo prazo $^{8}$, tal e qual fez o senador Saturnino Braga." (CHAVES, 2014, 120)

${ }^{5}$ O MDB passou de 87 para 165 deputados, e de 7 para 20 senadores. A representação da ARENA, para os mesmos cargos, caiu de 223 para 199 e de 59 para 46, respectivamente. SKIDMORE, T. Brasil: De Castelo a Tancredo. Rio de Janeiro: Paz e Terra, 1988.pág. 337..

6"Poderia concluir dizendo que, se este acordo for adiante neste momento e desta maneira, será um tripúdio sobre a Doutrina Monroe. Este perigo em potencial está sendo criado por um aliado, em nosso próprio quintal, enquanto os Estados Unidos estão fortemente empenhados em defender a Alemanha Ocidental do mesmo tipo de perigo potencial. " MIROW, K. Loucura Nuclear. Rio de Janeiro: Civilização Brasileira. 1979, pág. 45.

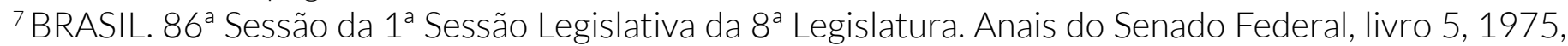
pág. 569.

8/dem, pág. 568. 
Coutto (2011) aponta que o Acordo era, na verdade, um conjunto de acordos comerciais, de salvaguardas e financiamento criado entre os governos e empresas privadas de ambos os países, colocados sob um "guarda-chuva", que foi o Acordo de 1975. Neste sentido encampava também diferentes interesses privados alemães.

Tabela 1: Empresas estabelecidas no Acordo de 1975:

\begin{tabular}{|c|l|l|}
\hline Empresa & \multicolumn{1}{|c|}{ Propriedade } & \multicolumn{1}{|c|}{ Objetivo } \\
\hline NUCLAM & Nuclebrás (51\%), Urangelesellschaft (49\%) & Prospecção, mineração e conversão. \\
\hline NUCLEP & $\begin{array}{l}\text { Nuclebrás, Kraftwerk Union (KWU), } \\
\text { GutehoffnungshutteSterkrage, Voest (Áustria) }\end{array}$ & Equipamentos pesados. \\
\hline NUCLEN & Nuclebrás, KWU com de potência, com & $\begin{array}{l}\text { Reatores der } \\
\text { nacionalização crescente. }\end{array}$ \\
\hline NUCLEI & $\begin{array}{l}\text { Nuclebrás (70\%), KWU, Reaquecimento isotópico. } \\
\text { Brennelement Union GmbH }\end{array}$ & $\begin{array}{l}\text { Desenvolvimento do Jet Nozzle, em } \\
\text { Essen, RFA. }\end{array}$ \\
\hline NUSTEG & Nuclebrás (50\%), Steag (50\%) & enriquecimento por Jet Nozzle. \\
\hline NUSTEP & $\begin{array}{l}\text { Nuclebrás (75\%), Steag AG (15\%), Interatom } \\
(10 \%)\end{array}$ & Monazita e associados. \\
\hline NUCLEMON & Criada apenas em 1977 & Reprocessamento. \\
\hline Consórcio & Nuclebrás, KEWA, Friedrich Uhde GmbH \\
\hline
\end{tabular}

O Programa Nuclear era desenvolvido pela NUCLEBRÁS, estatal criada para a gestão dos projetos decorrentes do Acordo e presidida pelo diplomata Paulo Nogueira Batista. Seu objetivo manifesto, a transferência de toda a tecnologia do ciclo nuclear, bem como a de construção de usinas nucleares, fez com que o Acordo, a princípio, fosse bem visto por diferentes setores. Concorreu para isso também o fato de o mesmo haver sido gestado em segredo, e apenas homologado pelo Congresso. Nesse sentido, a relação percebida entre o Acordo e desenvolvimento/autonomia, ancorada no nacionalismo, foi capaz de aparar as arestas entre diferentes grupos e garantir ao Programa Nuclear o apoio do Congresso.

O primeiro grupo a questionar o Acordo foram os especialistas em energia 
nuclear no Brasil, representantes da Sociedade Brasileira para o Progresso da Ciência (SBPC) e da Sociedade Brasileira de Física (SBF). Pouco após a assinatura do acordo entre Brasil e Alemanha, ocorreu a $27^{\circ}$ Reunião Anual da SBPC, e a surpresa da comunidade científica em relação ao acordo ${ }^{9}$ gerou uma série de reuniões fora do programa oficial do encontro, e logo ele tornou-se o tema central da reunião (SALINAS, 2001).

Como resultado dos debates promovidos durante o encontro, a SBF emitiu um boletim, aprovado pela assembleia da SBPC, que questionava os argumentos centrais do acordo. Além de questionamentos de ordem técnica (o Brasil conseguiria incorporar a tecnologia?, as técnicas a serem transferidas de fato funcionavam? Qual a real necessidade energética do Brasil? Qual o custo da energia nuclear frente às demais fontes?), os cientistas consideravam "indispensável que se discutam livre e amplamente os termos do acordo e suas implicações nos vários aspectos tecnológicos, econômicos, ecológicos e sociais da vida brasileira"10.

Não obstante, a posição entre os cientistas não era monolítica. Salinas (2001) aponta que a postura do então presidente da SBF, José Goldemberg, era de "cautela". Goldemberg, com apoio de José Israel Vargas, à época secretário de Ciência e Tecnologia de Minas Gerais, acreditava que o acordo trazia um sopro de positividade, ao apontar para o fato de que o verdadeiro objetivo brasileiro deveria ser a "independência nesse setor" e, portanto, estes the concediam um "apoio qualificado". O fato de acordo inicialmente prever transferência de tecnologia foi visto como um grande diferencial em relação à política anterior ${ }^{11}$.

Novamente o nacionalismo e a ideia de autonomia atenuavam críticas mais severas ao Acordo, mas já surgia aqui uma contestação da ideia de que o Acordo estava de alinhado aos interesses nacionalistas que o defendiam.

As críticas iniciais deram lugar a atritos entre o governo e estas organizações, frente às críticas que estas levantavam (CHAVES, 2014; OLIVEIRA, 1999;

${ }^{9}$ GOLDEMBERG, José. José Goldemberg (depoimento, 1976). Rio de Janeiro, CPDOC, 2010, pp. 109110. "E a gente não sabia, não é? A gente sabia algumas coisas, mas não sabia aquilo [Acordo]. Bom, no momento em que o [Israel] Vargas não sabe nada sobre alguma coisa que se refira à energia nuclear, eu não sei nada, o [Marcelo] Damy não sabe nada, se nós não sabemos, então os que sabem devem ser uns indivíduos de uma reputação científica que você pode questionar realmente."

10 Boletim n05/1975, Sociedade Brasileira de Física.

${ }^{11}$ Foreign Broadcast Information Service Daily Reports. SQN: 127276FAF9D8E238. Expert Interviewed on Nuclear Options.1975/07/18, Rio de Janeiro, Jornal Opinião. FBIS-LAT-75-144, DAILY REPORT. LatinAmerica- Page D1, D2, D3, D4. 
Ideias, interesses e escolha racional, pp. 27 - 42

ROSA, 1991; ROSA, 1985;). A NUCLEBRÁS chegou a proibir seus técnicos de participar de encontros das entidades em 1976², além de haver cortado o financiamento dos eventos em 1977¹3. Este quadro, já de certa maneira duradouro, de estranhamento entre o governo e a comunidade científica (NUNES, 1999) aproximava tanto elementos da oposição social quanto política destas organizações científicas. Neste momento já eram frequentes o contato entre cientistas e a comunidade científica, em especial o então senador Franco Montoro ${ }^{14}$.

Este contato é interessante, pois as críticas técnicas dos cientistas vão adquirindotonalidades políticasmais claras, encampandocríticasaoautoritarismo do governo e atrelando a questão do desenvolvimento nuclear à democratização (SALINAS, 2001; ROSA, 1991). Por outro lado, são os argumentos técnicos dos cientistas que dão base à crescente oposição parlamentar ao programa, que vai tomando força na medida em que diversos eventos comprovam sua argumentação de que o Acordo continha graves problemas e dificilmente seria levado a cabo, e que estes decorriam do viés autoritário sob o qual ele foi construído (CHAVES, 2014).

Portanto, entre 1975 e 1977, as organizações científicas se voltaram ao Acordo de 1975 e passaram a atacar suas incongruências. Foge aos objetivos deste trabalho expor as críticas pormenorizadas, mas algumas das principais críticas vinham do fato de que o método de enriquecimento de urânio a ser transferido não havia sido testado além da escala laboratorial e implicava em um custo proibitivo para a produção de energia em larga escala15; do preço excessivo que se pagava pelas máquinas alemãs e a baixa participação da indústria brasileira ${ }^{16}$; a grande probabilidade de o país não incorporar a tecnologia e o autoritarismo do processo de construção do Acordo.

Outro importante grupo que deixou de apoiar o programa nestes anos foi a indústria nacional. Após o aprofundamento do Choque do Petróleo de 1973, o crescimento econômico brasileiro passou a um patamar mais baixo, apesar de se manter positivo, enquanto o endividamento externo aumentava

\footnotetext{
12 Físicos criticam severamente a Nuclebrás. Folha de São Paulo, 10 de julho de 1976.

13 SBPC: Reunião Cancelada. Folha de São Paulo, 18 de junho de 1977

${ }^{14}$ E-mail de José Goldemberg ao autor, 28 de janeiro de 2014.

15 "[...] of the three existing methods, this [the Jet Nozzle] consumes more energy than the others and has yet not been tested on industrial level". FBIS Daily Reports, op. cit.

${ }^{16}$ Energia Nuclear será discutida em Reunião de Físicos. Folha de São Paulo, 06 de agosto de 1977.
}

CSOnline - Revista Eletrônica de Ciências Sociais, Juiz de Fora, n. 27 (2018) 
exponencialmente. Os grandes empresários brasileiros, acostumados ao padrão dos anos do "milagre", se irritavam com a excessiva intervenção do governo na economia, além de temer que a rápida expansão das estatais ameaçasse suas posições (SKIDMORE, 1988, 355). Severo Gomes, então ministro da Indústria e Comércio, foi uma das mais importantes vozes apontando a necessidade de liberalização da política e da economia brasileiras durante o ano de $1976^{17}$.

O Congresso Nacional das Classes Produtoras criou o lema "desestatizar!", que tinha como uma de suas origens a esperança de determinados setores empresariais de que sob um regime democrático "o empresariado teria mais chance de influenciar a política, especialmente contra os burocratas e os interesses das empresas estrangeiras que o autoritarismo havia favorecido" (IDEM, 393). O farto crédito externo criava uma situação em que importar máquinas e equipamentos do exterior era viável, ao passo em que o governo não dispunha de liquidez para comprar a produção nacional. Somem-se a isto as condições especiais que as empresas estrangeiras encontravam no país em determinados setores, sendo o nuclear um dos exemplos mais egrégios.

Em seu Loucura Nuclear, o industrial germano-brasileiro Kurt Rudolf Mirow descreve a posição do empresariado brasileiro em relação à energia nuclear. Einar Kok, então presidente da ABIMAQ (Associação Brasileira da Indústria de Máquinas) afirmou que a iniciativa privada brasileira respondera prontamente ao apelo do governo, em 1974, e fizera grandes investimentos em seus parques de produção, mas que no momento encontrava-se em uma "encruzilhada de decisões", pois não havia encomendas suficientes por parte do governo. Para o empresário Antônio Ermírio de Morais, o governo estava "trocando a matemática por adjetivos", e bastaria uma máquina de calcular para se constatar que o Brasil não dispunha dos recursos que se comprometera a gastar (MIROW, 205).

Estas insatisfações foram lentamente se integrando às discussões no Congresso, que num primeiro momento dera apoio quase irrestrito ao Acordo. Em 1977, Saturnino Braga (MDB) afirmou que o Brasil não necessitava de oito reatores, seja para pesquisa ou produção energética ${ }^{18}$. Dirceu Cardoso (MDB), por sua vez, questionou em que medida o Acordo traria independência:

${ }^{17}$ O presidente Ernesto Geisel pediu sua renúncia em princípios de 1977, em razão da ostensividade de seus comentários. Em maior detalhe, SKIDMORE, op. cit. 394

18 BRASIL. 189a à 201ª Sessão da $3^{\text {a }}$ Sessão Legislativa da $8^{a}$ Legislatura. Anais do Senado Federal, livro 14, 1977, pág 6675. 
Ideias, interesses e escolha racional, pp. 27 - 42

Esta crítica que fiz ao pacote para Angra dos Reis, da política nuclear, não é minha, - quem sou eu para falar em política nuclear - é o resultado da leitura de quase todos os cientistas nucleares brasileiros, quase todos, porque todos seria uma superfetação, talvez uma mentira, uma ousadia ou veleidade; mas aqueles que têm o mais alto gabarito, assim se expressam: que o Brasil está comprando máquinas. (BRASIL, 1977, 6390)

Neste ponto já existia uma ideia concorrente àquela que fundamentou a aceitação do Acordo. Pautada nas mesmas noções de independência, autonomia e nacionalismo, esta ideia colocava o Acordo como mais um processo a minálas. Uma nova percepção sobre o projeto, isto é, que ele não levaria o Brasil à independência, mas aprofundaria sua dependência, começa a tomar força. Com o aprofundamento das críticas da comunidade científica e da indústria nacional, o quadro começa a mudar no Congresso. Entre 1975 e 1978, discussões acerca da possiblidade de o programa nuclear alcançar seus objetivos começam a ser encampados pela oposição, bem como sobre a pouca participação dos cientistas brasileiros na elaboração do projeto, seu viés autoritário, dentre outros pontos (CHAVES, 2014).

O acirramento da oposição no Congresso chega a seu limite com a publicação de uma reportagem da revista alemã Der Spiegel, apontando diversas irregularidades no Acordo estabelecido em 197519. A denúncia foi central para a criação da CPI de 1978, que investigou o Acordo. É interessante notar que o requerimento para a abertura da Comissão foi assinado por membros da ARENA e MDB, muitos dos quais haviam apoiado a assinatura do Acordo (CHAVES, 2014). De acordo com Coutto, "os trabalhos da CPI mostram que a posição do Congresso brasileiro face ao acordo de 1975 não obedece à clivagem MDB-ARENA (ou seja, governo versus oposição) do sistema bipartidarista" (2011, 14). Ou seja, a recepção positiva ao acordo esteve fundamentada no nacionalismo, como já mencionado.

O surgimento de uma explicação alternativa sobre o papel do Acordo foi ganhando força, na medida em que grupos intermediários importantes, como a indústria nacional e as organizações científicas, começam a interpor críticas crescentes ao programa. Estas críticas viram objeto de disputa no Congresso até um evento externo, a publicação da revista Der Spiegel, se mostrar como uma corroboração das críticas levantadas. Neste momento o ator pivotal, o

19 Atomgeschaft: Milliarde-Pleite in Bresilien? Der Spiegel, 18 de setembro de 1978. Último acesso em 11/01/2014. Disponível em: http://www.spiegel.de/spiegel/print/d-40607111.html

CSOnline - Revista Eletrônica de Ciências Sociais, Juiz de Fora, n. 27 (2018) 
Ideias, interesses e escolha racional, pp. 27 - 42

Congresso Nacional, muda rapidamente sua posição sobre o tema, e instaura uma CPI para investigar o Acordo. A mudança deste ator, por sua vez, levou o governo a insular o Programa Nuclear, e ancorá-lo numa coalizão de atores com interesses distintos (dentre os quais figurava ainda o nacionalismo) num projeto que funcionava como uma "tela em branco", onde estes atores podiam projetar suas diferentes percepções (BARLETTA, 1997).

O que é interessante notar a respeito do acirramento da oposição ao acordo e na CPI que dele decorre, é que o mesmo nacionalismo que tornou possível uma recepção universalista do acordo foi capaz de engendrar e organizar uma oposição a ele. Elementos nacionalistas da ARENA, que haviam recepcionado o Acordo Brasil-Alemanha como o "acordo do século", foram confrontados com informações que reiteravam parte significativa das críticas à política nuclear. $\bigcirc$ fato de membros proeminentes da ARENA, como Teotônio Vilela e Magalhães Pinto - este saudado nominalmente por diversos oradores na data da assinatura do acordo - terem assinado o requerimento de instalação da CPI aponta para o processo de erosão da base de apoio nacionalista ao acordo de 1975. O Acordo passou a ser visto sob uma nova luz, e a noção de que ele traria independência e autonomia foi desterrada, fazendo com que, desde um ponto de vista nacionalista, ele se tornasse o oposto diametral do que era considerado em 1975. Numa discussão que diferenciasse os interesses de atores e suas estratégias, se poderia dizer que o interesse subjacente sempre foi o nacionalismo e que uma nova percepção sobre o Acordo mobilizou este mesmo nacionalismo contra ele, dando lugar a nova estratégia.

Do ponto de vista institucional, a CPI teve grande importância. Ao dar o golpe de misericórdia nas expectativas sobre o programa nuclear, sobre os preços das próprias usinas e da energia que produziriam, além de sobre a transferência de tecnologia, foi um dos principais incentivos para a criação de um programa autônomo. A Comissão abalou o animus que movia os seus defensores, cuja ação, neste campo, era informada pelo tripé nacionalismo-desenvolvimentoautonomia. A Comissão lançou dúvidas sobre os três aspectos.

Um dos resultados imediatos da CPI foi fomentar o consenso entre setores militares e o Executivo que, ainda sob o general Geisel, em 1978, fez a opção por uma via de desenvolvimento autônoma, criando o Programa Autônomo nos últimos dias de seu governo ${ }^{20}$. Ao passo em que a CPI recomendava transparência

20 Exposição de Motivos nº 011/85, de fevereiro de 1985. Da Secretaria-Geral do CSN ao Presidente da República. (Arquivo pessoal, CPDOC/FGV). Disponível em: http://digitalarchive.wilsoncenter.org/assets/ media_files/000/007/906/7906.pdf

CSOnline - Revista Eletrônica de Ciências Sociais, Juiz de Fora, n. 27 (2018) 
e fiscalização, o governo Geisel optou por aprofundar o insulamento burocrático do setor nuclear. A CNEN já podia ser considerada uma instituição insulada (NUNES, 1999, 35), mas a estrutura do Programa Autônomo encontrava-se no limite do insulamento, sendo secreta para todos, afora um pequeno e restrito círculo técnico-político do governo.

Esta opção resolveu alguns problemas - criou tecnologia nacional de enriquecimento num prazo notavelmente exíguo, por exemplo -, entretanto terminou por reacender a oposição ao Programa Nuclear anos mais tarde. 0 insulamento do período militar levava ao rompimento entre governo e diversos atores sociais (OAB, SBPC e o próprio Congresso, por exemplo), abrindo espaço para tensões em potencial, processo que, por sua vez, se intensificava ainda mais com a liberalização da Abertura.

\section{Conclusões}

Entender as razões pelas quais uma mesma legislatura recepcionou um acordo como um grande feito e poucos anos depois montou uma Comissão para investiga-lo requer investigar o papel das ideias e percepções dos atores que adotaram estas estratégias.

O nacionalismo é uma chave que explica bem a razão pela qual o Congresso recebeu bem o Acordo, fora da clivagem entre situação e oposição.

Mas é importante ressaltar também que a estrutura importa. O Brasil vivia um regime autoritário que, muito embora anunciasse suas intenções liberalizantes, era um regime autoritário. Neste sentido, como marcou o senador Lysâneas Maciel na data da ratificação da assinatura do Acordo pelo Congresso, o "MDB está[va] evitando discutir assuntos importantes, para assegurar-se o direito de mais tarde discutir assuntos supérfluos". Por mais que compartisse do nacionalismo da aceitação, ele tinha problemas com a não discussão dos detalhes do Acordo no Congresso. Não obstante, o custo de se colocar contra uma inciativa nacionalista do governo era demasiado alto para gerar uma oposição sistemática ao Acordo.

Os grupos intermediários também apoiavam a iniciativa a princípio. Os industriais nacionais haviam aceitado o desafio de ampliar sua produção com vistas no programa, cientistas viam como uma boa iniciativa perseguir a independência no setor nuclear. Mas foram estes grupos que começaram a ventilar a ideia de que, mesmo sob uma ótica nacionalista, o Acordo não teria 
resultados palpáveis, tampouco seria capaz de fazer o país caminhar na direção desejada.

Estas críticas estabelecem um desafio ao modelo corrente, isto é, de que - Brasil não só conseguiria incorporar toda a tecnologia alemã, como se tornaria mais independente e autônomo com o Acordo de 1975. As críticas, especialmente para este caso as de ordem técnica, quando técnicos e cientistas contestavam as explicações e objetivos do governo foram não só dando força à ideia alternativa, mas também tornando maiores as apostas para o caso de esta ideia alternativa estar certa - o país não só gastaria dinheiro e se endividaria, mas também se tornaria mais dependente de tecnologia estrangeira e insuficiente energeticamente.

O evento externo que confirma esta visão são as denúncias da imprensa alemã que levantam diversos temas já apontados por industriais e cientistas, além de apontar outros possíveis problemas. Este evento é a "gota d'água", ou o ponto crítico de Weingast, que leva o ator pivotal - o Congresso - a mudar sua posição e desestabilizar o Programa Nuclear, levando a um rápido rearranjo institucional.

\section{Bibliografia}

BARLETTA, Michael. The Military Nuclear Program in Brazil, (Centre for International Security and Arms Control,Stanford University; August 1997)

CAMARGO, G. O Fogo dos Deuses: Uma História da Energia Nuclear. Rio de Janeiro, Editora Contraponto, 2006

CAPOCCIA, G; KELEMEN, R. The Study of Critical Junctures Theory, Narrative, and Counterfactuals in Historical Institutionalism. World Politics 59 (April 2007), 341-69

COUTTO, T. O Papel das Comissões Parlamentares de Inquérito na Política Nuclear Brasileira: A CPI de 1978 e o Acordo Nuclear Brasil-Alemanha. MAST, Rio de Janeiro, 2011

CHAVES, R. O Programa Nuclear a Construção da democracia: Análise da oposição ao programa nuclear brasileiro (1975-1990). Rio de Janeiro, 2014. 
Ideias, interesses e escolha racional, pp. 27 - 42

GOLDEMBERG, José. José Goldemberg (depoimento, 1976). Rio de Janeiro, CPDOC, 2010

MAHONEY, J. and THELEN, K. (eds.) (2009) Explaining Institutional Change: Ambiguity, Agency, and Power

MIROW, K. Loucura Nuclear. Rio de Janeiro: Civilização Brasileira. 1979

NUNES, E. A Gramática Política do Brasil: Clientelismo e Insulamento burocrático. Rio de Janeiro: Jorge Zahar Editora. 1997, $2^{\text {a ed. }}$

OLIVEIRA, O. Os Descaminhos do Brasil Nuclear.ljuí: Unijuí, 1999

SALINAS, Silvio R. A. Notas para uma História da Sociedade Brasileira de Física. Rev. Bras. De Ensino de Física, vol. 3, n²3, 2001.

NORTH, D. C. 1990. Institutions, Institutional Change, and Economic Performance. Cambridge: Cambridge University Press

PATTI, C. Brazil in the Global Nuclear Order. Firenze, 2010

PIERSON, P. "Increasing Returns, Path Dependence, and the Study of Politics," American Political Science Review 94 (Junho 2000)

ROSA, L et al. Política Nuclear no Brasil.1991. São Paulo. Greenpeace . A Política Nuclear e o Caminho das Armas Atômicas. Rio de Janeiro: Jorge Zahar Editora, 1985

SKIDMORE, T. Brasil: De Castelo a Tancredo. Rio de Janeiro: Paz e Terra, 1988

WEINGAST, B. Persuasion, Preference Change, and Critical Junctures: The microfoundation of a macroscopic concept. IN: KTATZNELSON, I; WEINGAST, B. Preferences and Situations: Points of intersection between historical and rational choice institucionalism. Sage Foundation, New York, 2005. 